Revista Destaques Acadêmicos, Lajeado, v. 12, n. 2, 2020. ISSN 2176-3070

DOI: http://dx.doi.org/10.22410/issn.2176-3070.v12i2a2020.2568

http://www.univates.br/revistas

\title{
EDUCAÇÃO DO CAMPO: A ESCOLA MUNICIPAL BOM JESUS NA PERCEPÇÃO DOS ATORES SOCIAIS ENVOLVIDOS
}

\author{
Edilaine Ferreira Leal ${ }^{1}$, Marcelo Franco Leão
}

\begin{abstract}
Resumo: A Educação do Campo surgiu como uma forma de ofertar instrução e atender as especificidades das pessoas que trabalham ou vivem no/do campo. Essa modalidade educacional é relativamente recente e fruto de grandes lutas sociais. Esse estudo tem como objetivo refletir as percepções dos atores sociais da Escola Municipal Bom Jesus, Santa Terezinha/MT, sobre a educação do campo vivenciada, a importância da escola, seus desafios, sua interação com a comunidade e as perspectivas futuras. Esta pesquisa de cunho qualitativo, toma por base as percepções dos diferentes segmentos que constituem a comunidade escolar desta instituição voltada ao atendimento a moradores do campo. Para coletar dados, no decorrer do primeiro semestre de 2019, foram realizadas aplicações de questionários com moradores, pais e alunos, além de pesquisas na literatura e documentos oficiais, que serviram como aporte teórico. Sobre a importância da escola, destaca-se que a mesma se constitui como espaço de socialização e oportunidade de participação da comunidade. Sobre a interação escola e comunidade e as perspectivas, foram mencionadas as percepções de que a escola promove a interação com seus grupos por meio das feiras de vendas de produtos, reuniões e eventos. No entanto, como desafios tivemos relatos de que a escola ainda permanece distante da história local e das questões inerentes aos saberes populares. Logo, essa modalidade necessita de políticas educacionais para que de fato cumpra sua finalidade e supere a fragilidade no que diz respeito à construção de um currículo próprio que atenda às especificidades das comunidades locais.
\end{abstract}

Palavras-chave: Desafios educacionais. Educação do Campo. Práticas pedagógicas.

1 Licenciada e Bacharel em Ciências Sociais: Antropologia, Ciência Política e Sociologia (UNEMAT). Pós-Graduada em Educação do Campo (IFMT). Professora da Escola Estadual Professora Maria Esther Peres (SEDUC/MT), município de Vila Rica.

2 Graduado em Licenciatura em Química (UNISC)e em Física (UNEMAT). Pós-graduado em Orientação Educacional(Dom Alberto) e em Relações Raciais na Educação e na sociedade Brasileira(UFMT). Mestre em Ensino (UNIVATES). Doutor em Educação em Ciências (UFRGS). Professor do IFMT Campus Confresa-MT. 


\section{INTRODUÇÃO}

A educação pode ser compreendida, tanto no âmbito escolar quanto em outros ambientes, onde os processos de formação de aprendizagem e desenvolvimento das habilidades acontecem. Neste sentido, a Lei de Diretrizes e Bases da Educação Nacional (LDBEN), em seu artigo $1^{\circ}$, caracteriza a educação como sendo aquilo que abrange os processos formativos que se desenvolvem na vida familiar, na convivência humana, no trabalho, nas instituições de ensino e pesquisa, nos movimentos sociais e organizações da sociedade civil e nas manifestações culturais (BRASIL, 1996).

Diante disso, torna-se pertinente a reflexão acerca das especificidades e desafios da Educação do Campo. Assim, o presente estudo busca discutir a realidade da Educação do Campo, com a intenção de identificar por meio de pesquisas qualitativas as principais problemáticas, desafios e perspectivas no entorno desse modelo de ensino. Parte-se do pressuposto que discutir sobre a Educação do Campo vivenciada em um determinado contexto, viabiliza buscar características quanto as suas origens, suas perspectivas, as metodologias de ensino mais adequadas, medidas e ações já realizadas, bem como as perspectivas futuras dos atores sociais envolvidos.

A temática escolhida se justifica pelo interesse da pesquisadora em buscar compreensões acerca da escola a qual estudou toda sua infância. O intuito, era o de retornar às origens e compreender qual a importância da escola para alunos, pais e moradores da comunidade.

Sendo assim, o problema que norteou esse estudo foi: Quais as percepções dos atores sociais da Escola Municipal Bom Jesus, Santa Terezinha/MT, sobre a educação do campo vivenciada, seus problemas, desafios e perspectivas?

Para solucionar tal problema, foi realizado um levantamento de dados por meio da aplicação de questionários com moradores, pais e alunos além da pesquisa bibliográfica, documental e histórica a respeito da instituição de ensino e da comunidade, suas concepções acerca da escola e das práticas adotadas no cotidiano escolar.

Este estudo é fruto de uma pesquisa realizada com a comunidade escolar da Escola Municipal Bom Jesus localizada no Projeto de Assentamento Reunidas I em Santa Terezinha/MT, considerando que a educação do campo ainda é alvo de muitos questionamentos por apontar fragilidades e desafios para a construção de um currículo que venha a efetivar uma educação emancipadora aos povos do campo.

\section{REFLEXÕES TEÓRICAS SOBRE A EDUCAÇÃO DO CAMPO}

Refletir sobre a Educação do Campo nos remete a realizar um retrospecto de um longo período de lutas e conflitos para a busca da consolidação dessa 
modalidade, sem deixar de ressaltar as inúmeras contradições e transformações nas políticas públicas educacionais que vem acontecendo no Brasil.

Nesse sentido, ao se tratar da Educação do Campo, Caldart, (2012) a nomeia como um fenômeno da realidade brasileira atual, protagonizado pelos trabalhadores do campo e suas organizações, que visa incidir sobre a política de educação desde os interesses sociais das comunidades camponesas.

Assim sendo, a luta dos trabalhadores do campo busca garantir e efetivar os direitos de quem vive no campo de ter acesso a uma escola que seja pensada dentro de suas especificidades. Ainda nesse contexto, é o que afirma Arroyo (2007, p. 9):

Advinda da organização dos movimentos sociais, a educação do campo nasce em contraposição à educação rural. A educação do campo é uma forma de reconhecimento dos direitos das pessoas que vivem no campo, no sentido de terem uma educação diferenciada dessa perspectiva, como também daquela que é oferecida aos habitantes das áreas urbanas. Surge, assim, de forma "repensada e desafiante".

Desse modo, trata-se de reconhecer a Educação do Campo como especificidade educacional e proporcionar aos moradores do campo, conhecimentos próprios do lugar onde vivem.

Deve-se levar em consideração que esse reconhecimento de que a Educação do Campo tem que ser diferenciada no sentido de assumir o compromisso de auxiliar e fortalecer as práticas sociais características das populações locais pode ser compreendido como processo recente e inovador que foi fortalecido a partir da instituição, pelo Conselho Nacional de Educação, das Diretrizes Operacionais para a Educação Básica nas Escolas do Campo, conforme a Resolução do CNE/CEB n ${ }^{\circ}$ de 03/04/2002. Este conselho foi instituído com o propósito de criar métodos e formas próprias que atendessem as especificidades educacionais dos povos do campo, respeitando seus modos de se relacionar com a terra (BRASIL, 2007).

Nesse sentido, iniciam-se as lutas pelo direito de acesso à educação e à escolarização no campo e pela construção de uma escola que atenda aos anseios e ideais dos povos do campo com todas suas particularidades, estabelecendo uma identidade que é própria do campo. Essa definição de escola do campo está mencionada no parágrafo único do art. $2^{\circ}$ das Diretrizes Operacionais para a Educação Básica nas Escolas do Campo:

A identidade da escola do campo é definida pela sua vinculação às questões inerentes a sua realidade, ancorando-se na sua temporalidade e saberes próprios dos estudantes, na memória coletiva que sinaliza futuros, na rede de Ciência e Tecnologia disponível na Sociedade e nos Movimentos Sociais em defesa de 
projetos que associem as soluções por essas questões à qualidade social da vida coletiva no país (BRASIL, 2002, p. 37).

Desse modo, não se pode pensar em uma escola do campo distanciandose dos reais objetivos pelos quais ela está pautada, atender aos povos do campo e formá-los no sentido de compreender, valorizar e dar continuidade aos saberes populares, tendo a possibilidade de buscar o desenvolvimento do campo por meio dos conhecimentos proporcionados pela escola com bases necessárias para que o jovem possa permanecer no campo.

As Diretrizes Operacionais para a Educação Básica nas Escolas do Campo (BRASIL, 2002) revelam que as tensões e contradições acerca da Educação do Campo representam uma enorme fragilidade de um país que mesmo sendo desde sua origem em grande parte agrário, sequer teve a questão do atendimento educacional aos povos do campo mencionado no texto da constituição de 1824 e 1891.

A educação existente se contextualizava como Educação Rural, que não atendia as especificidades dos povos do campo, ou seja, pode-se dizer que a educação era objeto de monopólio das elites e, nesse sentido, havia uma grande "migração" sentido campo/cidade na busca de uma melhor oferta e qualidade de ensino, que até então não recebia investimentos e incentivos necessários para as escolas do campo

Aos poucos, começa-se a criar programas, que visavam a permanência do homem no campo. Essas iniciativas, na maioria das vezes, buscavam melhoria na qualidade de vida, mas não levavam em consideração as peculiaridades específicas do campo (BRASIL, 2007). A educação se desenvolvia no sentido de proteger e dar assistência ao camponês que até então era visto como pobre, subnutrido e ignorante.

Somente a partir da aprovação da nova Lei de Diretrizes de Bases da Educação Nacional (LDB) n 9394/96 fica assegurado e passa a reconhecer a diversidade do campo e em vários artigos estabelece orientações para atender à realidade do campo fazendo adaptações conforme suas peculiaridades. No artigo 28 da LDB, fica estabelecido:

$\mathrm{Na}$ oferta da educação básica para a população rural, os sistemas de ensino proverão as adaptações necessárias à sua adequação, às peculiaridades da vida rural e de cada região, especialmente: I - conteúdos curriculares e metodologia apropriadas às reais necessidades e interesses dos alunos da zona rural; II - organização escolar própria, incluindo a adequação do calendário escolar às fases do ciclo agrícola e às condições climáticas; III - adequação à natureza do trabalho na zona rural (BRASIL, 1996, Art. 28º).

Nesse sentido, o artigo 28, ao reconhecer as peculiaridades educacionais do campo ainda possibilita às escolas sua organização de forma que venha 
atender sua realidade e contemplar o conhecimento vinculado ao contexto que está inserido, deve-se levar em consideração que a Educação do Campo deve ser construída de acordo com a realidade do local onde está inserida.

As Diretrizes Operacionais para Educação do Campo definem, em seu segundo artigo, que educação na perspectiva da Educação do Campo é:

A identidade da escola do campo é definida pela sua vinculação às questões inerentes à sua realidade, ancorando-se na temporalidade e saberes próprios dos estudantes, na memória coletiva que sinaliza futuros, na rede de ciência e tecnologia disponível na sociedade e nos movimentos sociais em defesa de projetos que associem as soluções exigidas por essas questões à qualidade social da vida coletiva no país (BRASIL, 2002, Art. 2º , Parágrafo único).

Nesse sentido, a Educação do Campo se configura em um espaço de entraves, caracterizado pela busca de igualdade de direitos e oportunidades é uma luta dos trabalhadores pela dignidade e permanência na terra.

É preciso elucidar que não basta a escola estar geograficamente inserida no campo, é necessário que contribua ativamente para o melhoramento das práticas e técnicas usadas pelos camponeses, é necessário compreender ainda que tratam de realidades diferenciadas, onde as escolas do campo buscam respeitar as culturas locais e valorizá-las.

Sobre esse contexto, é o que afirma Caldart (2011, p. 110):

Uma escola do campo não é, afinal, um tipo diferente de escola, mas sim é a escola reconhecendo e ajudando a fortalecer os povos do campo como sujeitos sociais que também podem ajudar no processo de humanização do conjunto da sociedade, com suas lutas, sua história, seu trabalho, seus saberes, sua cultura, seu jeito.

Compreender e ressignificar os saberes locais de forma que contribua para melhorar a qualidade de vida da comunidade local, é a tarefa da Escola do Campo. Essa escola do campo precisa ser vista além dos limites do saber e aprender ler e escrever, pois várias são as relações sociais que estão imbuídas na realidade de uma escola do campo. Escola essa que não pode permanecer alheia às singularidades da comunidade que atende, uma vez que a escola é, para os povos do campo, um espaço de lazer, festividades e outros rituais que celebram e partilham momentos de saberes culturais próprios daquela comunidade.

\section{PROCEDIMENTOS METODOLÓGICOS}

Para iniciar as abordagens sobre a Educação do Campo, torna necessário primeiramente pensar a Educação de forma geral, seus objetivos e finalidades. Com este estudo buscamos promover uma reflexão entre a proposta legitimada 
de escola do campo e as percepções dos atores sociais diretamente envolvidos com o processo educativo da unidade escolar pesquisada.

Para dialogar com a proposta da educação do campo enquanto diversidade educacional, buscamos dados com pais, alunos e comunidade de modo geral para compreendermos como a escola tem atendido ao propósito de formação que fortaleça as práticas sociais adotadas na comunidade.

Elaboramos um questionário que foi aplicado e preenchido pela própria pesquisadora onde foi perguntado dentre outras questões sobre como a escola promove a interação com a comunidade e como os saberes produzidos no ambiente escolar contribuem para o cotidiano do trabalhador do campo.

Para esse levantamento de dados, utilizamos a pesquisa de campo, onde visitamos alguns moradores e pais de alunos para coletar as informações de modo mais espontâneo. Também foram feitas visitas à escola para coletar informações junto aos alunos e documentos históricos para análises que nos permitiram finalizar nossas reflexões.

Participaram desse estudo 06 moradores locais e 06 alunos da escola. Todos os participantes foram previamente informados sobre os objetivos da pesquisa e decidiram participar voluntariamente, autorizando a divulgação de suas respostas e posicionamentos ao assinar o Termo de Consentimento Livre e Esclarecido (TCLE). Para garantir o anonimato dos participantes da pesquisa, os nomes foram substituídos pelos termos Aluno A, Aluno B, Morador G, Morador $\mathrm{H}$ e assim consecutivamente.

Para coletar os dados foram utilizados dois diferentes questionários, um deles direcionado para os pais e/ou integrantes da comunidade, e o outro voltado para os alunos da escola. Ambos questionários foram constituídos por 6 perguntas abertas cada.

O primeiro tipo continha as seguintes perguntas: 1) Qual a importância da escola para o assentamento e para sua vida? 2) A escola atende as necessidades do homem do campo? Quais são atendidas e quais não são? 3) Na sua concepção a escola respeita e valoriza a diversidade do campo? 4) Pelo que você percebe, existe uma relação entre o que se ensina na escola com o trabalho desenvolvido nas propriedades rurais? Dê exemplos: 5) Existem parcerias entre escola e comunidade (assentamento)? Quais? 6) De que forma a escola contribui para o fortalecimento do assentamento?

O segundo tipo de questionário (voltado para os alunos), continha as seguintes perguntas: 1) Qual a importância da escola para sua vida e para a vida do homem do campo? 2) A escola atende suas necessidades cotidianas lhe preparando para viver no campo? Quais são atendidas e quais não são? 3) De que maneira a escola trabalha a diversidade do campo? 4) Existe uma relação entre o que se ensina na escola com o trabalho desenvolvido nas propriedades rurais? Dê exemplos: 5) Quais atividades você percebe que a escola envolve a 
comunidade do assentamento? 6) Você considera que a escola contribui para o fortalecimento do homem do campo e do assentamento? Como?

Os dados coletados foram tabulados por categorias, sendo elas a importância da escola no atendimento das necessidades; desafios na valorização do homem do campo; a interação escola e comunidade e as perspectivas futuras dos participantes. Essas categorias foram analisadas tendo como suporte a teoria que sustentou a pesquisa.

\section{RESULTADOS E DISCUSSÃO}

Os resultados coletados apontam para uma realidade de construção de proposta de educação que busca aproximar a escola e a comunidade por meio das suas práticas educativas cotidianas. Tal construção tem se dado de modo lento e cheio de desafios como nos mostra alguns dos depoimentos fornecidos que serão apresentados a seguir.

Os resultados dos questionários aplicados dialogaram com as ideias de Caldart (2005) e Fernandes e Molina (2005) que referenciam a Educação do Campo. Tais resultados serão apresentados por categorias para a discussão/ reflexão.

A primeira categoria refere-se à importância da escola no atendimento das necessidades do homem do campo. Essa categoria foi identificada nas respostas fornecidas aos dois primeiros questionamentos aos moradores e aos alunos. Seguem algumas respostas que ilustram o pensamento dos participantes.

A escola representa o espaço de alcançar nossos objetivos, como oportunidade de cursar uma universidade com cursos que tenham ligação com o lugar que vivemos. A escola atende parcialmente nossas necessidades, pois nos dá acesso a informações que não conseguimos fora dela, as teorias. Mas, vejo também que a escola não atende nossas necessidades porque não é trabalhado aqui a questão da história de como se formou o assentamento, de como conseguiram trazer a escola pra cá. Isso a gente só fica sabendo quando pergunta para os moradores mais antigos (Aluna A).

Desta forma, Caldart (2005) destaca a importância de pensar a Educação do Campo por meio da práxis, para isso apresenta três desafios para a consolidação deste projeto. Sendo eles:

Manter viva a memória da Educação do Campo, continuando e dinamizando sua construção e reconstrução pelos seus próprios sujeitos; identificar as dimensões fundamentais da luta política a ser feita no momento atual; e seguir na construção do projeto político e pedagógico da Educação do Campo (CALDART, 2005, p. 2). 
A escola precisa construir essa relação de participação com os sujeitos que dela fazem parte. Os depoimentos abaixo, retratam a percepção da escola como espaço fundamental para a socialização:

A escola é muito importante porque além de ser uma excelente oportunidade de aprendizagem também é lugar de fazer amizades, pois aqui no campo, nosso local de encontrar os amigos é na escola, então acho muito importante para nós alunos e para a comunidade toda também (Aluno F).

Seguindo essa linha de pensamento, demonstramos a fala de um morador da comunidade:

Eu penso que a escola atende sim nossas necessidades, pois nossos filhos e netos aprendem lá "e outra", a escola sempre está aberta para os moradores ter acesso às reuniões que tratam das nossas terras. Também penso que a escola ajuda a gente até na nossa comunicação porque é lá que nós vamos para ter acesso à internet para resolver nossos problemas (Morador G).

Nos trechos acima temos a concepção de uma escola que está ligada com as questões inerentes à sua localização e ao seu tempo encontrando-se relativamente preocupada em garantir a participação de seus sujeitos na vida escolar e da comunidade.

A segunda categoria refere-se às formas como as diversidades do campo são trabalhadas na escola, bem como se existe relação com os conteúdos trabalhados e as atividades desenvolvidas nas propriedades rurais. Essa categoria foi identificada nas respostas fornecidas ao terceiro e quarto questionamento, tanto dos moradores quanto dos alunos. Seguem algumas respostas que ilustram o pensamento dos participantes.

Sobre os saberes produzidos no ambiente escolar contribuir para o fortalecimento do trabalhador do campo, demonstramos algumas respostas que obtivemos: "A escola nos incentiva a produzir artesanatos e alimentos, que depois poderemos vender nas feiras que a escola mesmo faz" (Aluna B).

Assim entendemos que a escola do campo se organiza em tempos, espaços e necessidades que podem variar de acordo com o contexto social. Como podemos notar no depoimento abaixo:

A escola desenvolveu uma horta sustentável e solidária durante algum tempo, que nos dava incentivo de produzir nas nossas propriedades, pois nossas crianças aprendiam na escola como lidar com a horta e nos ajudava em casa. É uma pena que o projeto só durou dois anos e acabou (Mãe de aluno H). 
O ponto de partida para a construção de saberes significativos na escola do campo deve ser as próprias singularidades da comunidade a qual a escola está inserida. Conforme destacam Fernandes e Molina, (2005, p. 68):

Esta visão do campo como um espaço que tem suas particularidades e que é ao mesmo tempo um campo de possibilidades de relação dos seres humanos com a produção das condições de existência social confere à Educação do Campo o papel de fomentar reflexões que acumulem força e espaço no sentido de contribuir na desconstrução do imaginário coletivo sobre a visão hierárquica que há entre campo e cidade; sobre a visão tradicional do jeca tatu, do campo como lugar do atraso.

No que se refere à relação entre os conteúdos trabalhados e as atividades desenvolvidas na comunidade, notamos que ainda existe um distanciamento entre a construção de um currículo que atenda as especificidades do campo. Como podemos notar nos depoimentos abaixo:

Não consigo ver essa relação não, pois na escola nunca nos foi ensinado sobre como "cubar" terra, madeira... essas coisas eu acho que deveriam ser ensinadas aqui, por que a gente usa muito esse conhecimento e sempre que precisamos, temos que procurar os vizinhos que sabem fazer esses cálculos (Aluno C).

Sobre esse distanciamento entre os conteúdos trabalhados na escola e a aplicação dos conhecimentos adquiridos na comunidade, temos o depoimento a seguir "Eu acho que a escola só ensina mesmo o que as outras escolas da cidade ensinam. Não tem muita relação com as coisas que fazemos aqui na roça não" (Morador I).

Desse modo, é necessário repensar as práticas cotidianas da escola, pois, em conformidade com Fernandes e Molina (2005), a Educação do Campo se indissocia da reflexão sobre um novo modelo de desenvolvimento e o papel para o campo nele.

Desse modo, podemos observar que a escola se esmera a cuidar da Educação do Campo, posto que as vivências cidadãs não precisam apenas estar alojadas na urbanidade das cidades, mas que continuem sendo almejadas pelos estudantes têm uma história que guarda a riqueza cultural do campo.

A escola apresenta em seu Projeto Político Pedagógico a concepção de escola do campo que busca pesquisar e apontar possíveis caminhos para o fortalecimento das práticas sociais adotadas na comunidade "A escola está em processo de introdução da pesquisa no campo e voltada para o campo, de modo que trabalhe a realidade do aluno, do pequeno produtor e agricultor, envolvendo teoria e prática" (PPP, 2019). 
A última categoria está relacionada com a interação escola e comunidade e as perspectivas futuras dos participantes. Essa categoria foi identificada a partir dos dois últimos questionamentos. Quando perguntamos sobre a interação entre escola e comunidade, obtivemos como respostas alguns exemplos que a escola adota de realizar periodicamente feiras de venda dos produtos oriundos da agricultura familiar, eventos culturais e reuniões com a comunidade. Destacamos a seguir, alguns desses posicionamentos.

A escola é o lugar de nossos encontros, reuniões e tudo que é sobre nossa situação com a terra é feito na escola. Também é um lugar de apoio para consultas médicas e atendimento com vacinas para toda a comunidade. Então vejo que é na escola que encontramos esse tipo de apoio (Morador J).

Seguindo esse questionamento da relação escola/comunidade, um aluno pontuou algo bastante parecido com o depoimento acima: "Eu vejo que a escola é que une a comunidade porque é aqui que acontecem as reuniões e discussões sobre a terra e sobre futuros projetos que melhorem nossa vida aqui no campo" (Aluno D).

Ainda sobre essa interação escola/comunidade, um pai de aluno destacou um dos pontos que considera mais importantes desenvolvidos pela escola.

Eu vejo na escola uma oportunidade de vender meus produtos (queijos, ovos, frangos, banana, mandioca, etc.), pois eles fazem a feira do preço justo e a gente pode vender e comprar tudo que nós produzimos aqui. Eu acho muito bom porque nossos produtos não perdem e nem precisamos levar na cidade para vender (Pai de aluno $\mathrm{K})$.

Caldart (2005, p. 65) aponta para a compreensão de escola que se configura em organização coletiva, trabalhando os interesses dos grupos que a compõe e construindo uma identidade própria.

Se a escola do campo é aquela que trabalha desde os interesses, a política, a cultura e a economia dos diversos grupos de trabalhadores e trabalhadoras do campo, ela somente será construída deste jeito, se os povos do campo, em sua identidade e diversidade, assumirem este desafio. Não sozinhos, mas também não sem sua própria luta e organização.

É interessante notar como que a permanência no campo está diretamente ligada à possibilidade de os filhos frequentarem a escola. Como nos aponta $\mathrm{o}$ depoimento a seguir: "Nossos pais não sentem vontade de sair daqui porque tem a escola para gente continuar estudando. Eles valorizam muito nossos 
estudos, então a escola contribui e muito para que o assentamento continue forte, com muitos moradores" (Aluno E).

Sobre esse entendimento, Caldart (2005, p. 68) ressalta:

Oestudo, entendidobasicamente comoeste processo deinterpretação da realidade para poder transformá-la, é um componente importante na constituição e no fortalecimento dos sujeitos sociais, sejam eles do campo ou da cidade. Neste sentido, o acesso a lugares onde se possa desenvolver a cultura do estudo é um direito que o movimento da luta transforma também em dever.

As percepções de moradores da comunidade, pais e alunos aqui demonstradas apontam para a necessidade de (re)elaborar uma proposta pedagógica que se conecte com as particularidades da comunidade local, uma vez que as propostas até então desenvolvidas, aparecem descontextualizadas e mal compreendidas pelos grupos que compõem a comunidade escolar.

\section{CONSIDERAÇÕES FINAIS}

Neste estudo apresentamos algumas reflexões sobre os desafios enfrentados pela escola para a consolidação de uma educação que atenda aos anseios de quem vive no campo. Os resultados apontam para a criação de um movimento ainda incipiente de uma concepção de educação do campo que extrapola os espaços escolares, se caracterizando como especificidade local, multiplicidade de saberes, ligação entre comunidade, práticas sociais e escola.

A escola que é do Campo pode até ser vista como uma escola que tem, aos poucos, procurado criar os próprios moldes do ensinar em conjunto com os saberes locais. No entanto, apresenta-se ainda como uma escola localizada no campo, mas ligada ao atendimento dos anseios de pessoas como se vivessem nas cidades ou grandes centros.

Desse modo, podemos entender que a construção de um currículo próprio para a escola será possível mediante a estreita participação de todos os segmentos que compõem a comunidade escolar, recriando espaços, tempos e ações que façam da escola do campo um espaço de aprendizagens múltiplas e significativas. Essa é uma resistência necessária para os tempos que se busca uma padronização dos estudos, a partir de um currículo comum para todas as regiões do Brasil.

Mesmo nesse período de descaso com a educação pelos poderes públicos, se percebem iniciativas como a que foi aqui relatava, a qual mostra que a vida em sociedade é dinâmica e também exige o cuidado atento e constante sobre a formação dos jovens que se profissionalizam a cuidar e gostar de viver no campo - espaço mais que importante para a própria sobrevivência das cidades. 
Logo, entendemos que é necessário fortalecer esse movimento, com vistas a um projeto coletivo consistente e legítimo que promova a transformação da educação e emancipação dos trabalhadores locais e rompa definitivamente com a ideia de uma escola do campo que atende aos ideais urbanos.

\section{REFERÊNCIAS}

ARROYO, Miguel Gonzalez. Políticas de formação de educadores (as) de campo. Cad. Cedes, Campinas, vol. 27, n. 72, p. 157-176, maio/ago., 2007. Disponível em: http:// www.cedes.unicamp.br. Acesso em: 29 de mar. 2019.

BRASIL: Lei de Diretrizes e Bases da Educação Nacional. 1996.

. Diretrizes Operacionais para a Educação Básica nas Escolas do Campo. De 03 de abril de 2002. Brasília: Conselho Nacional de Educação/Câmara de Educação Básica, 2002. Disponível em: http:/ / portal.mec.gov.br/index.php?option=com_ docman\&view=download\&alias=13800-rceb001-02-pdf\&category_slug=agosto-2013pdf\&Itemid=30192 Acesso em: 29 de mar. 2019.

. Ministério da Educação, Secretaria de Educação Continuada, alfabetização e Diversidade. Referência para uma política Nacional de Educação do Campo: caderno de subsídios. Coordenação: Marise Nogueira Ramos, Telma Maria Moreira, Clarice Aparecida dos Santos -2. ed. - Brasília; MEC, SECAD, 2007.

CALDART, Roseli Salete. A escola do campo em movimento. In: CALDART, Roseli Salete. Por uma educação do campo. Rio de Janeiro: Vozes, 2011.

Sobre educação do campo. III Seminário do Programa Nacional de Educação na Reforma Agrária (PRONERA). Luziânia, Goiás, 2012. Disponível <http://web2.ufes.br/educacaodocampo/down/cdrom1/ii_03.html> Acesso em 19 de maio de 2019.

. Elementos para a construção de um projeto político-pedagógico. Cadernos Temáticos: Educação do Campo. Curitiba: SEED, 2005, p 23-34.

. Educação do Campo. In: CALDART, Roseli et al. Dicionário da Educação do Campo. 2. ed. Rio de Janeiro-São Paulo: Escola Politécnica de Saúde Joaquim Venâncio, Expressão Popular, 2012.

FERNANDES, Bernardo Maçando. MOLINA, Mônica Castagna. O campo da Educação do Campo. IN: MOLINA, Mônica Castagna e JESUS, Sonia M.S.A. (Orgs.). Por uma educação do campo - contribuições para a construção de um projeto de Educação do Campo. 2. ed. Brasília, DF: Articulação Nacional "Por uma Educação do Campo", 2005.

PPP. Projeto Político Pedagógico. Escola Municipal Bom Jesus. Santa Terezinha, 2019. 